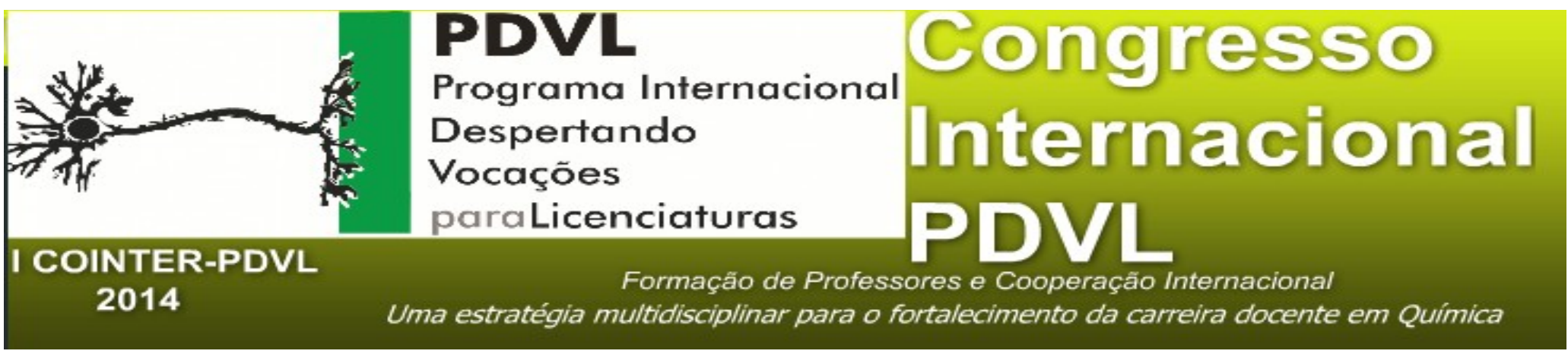

\title{
RELAÇÕES DE GÊNERO NO CONTEXTO DA MATA SUL DE PERNAMBUCO: UMA INVESTIGAÇÃO EDUCATIVA
}

\author{
Apresentação: Pôster

\section{Nielson da Silvia Bezerra; Mylena Lahana Gouveia Peixoto} \\ IFPE campus Barreiros $\backslash$ nielson.bezerra@barreiros.ifpe.edu.br \\ IFPE campus Barreiros\mylenalahana@hotmail.com
}

\section{Introdução}

Nossa pesquisa está inserida no arco de estratégias desenvolvidas no projeto Agroecologia, Agricultura Orgânica e Desenvolvimento Sustentável na zona da Mata Sul de Pernambuco, e é fruto dos esforços conjuntos realizado entre os curso superiores de Tecnólogo em Agroecologia e Licenciatura de Química do IFPE campus Barreiros. Considerando que Relações de Gênero desiguais afetam nossa sociedade de uma forma estrutural, e que a formação de professores não deve ficar de fora dessa discussão, nosso estudo volta-se para a Relação entre Meio Rural, Relações de Gênero e Formação de Professores de Química, buscando traçar sentidos a partir dos desafios que nossa realidade de ex-escola agrotécnica federal que busca hoje, como Instituto Federal de Educação, Ciência e Tecnologia formar professores de Química atentos a questões locais e mundiais.

\section{Fundamentação teórica}

Nosso interesse reside nos processos de construção das Relações de Gênero que ocorrem enquanto fenômenos educativos históricos, de cunho moral e didático-pedagógico, nos espaços formais e não formais de educação. Compreendemos que a escola não é um espaço em que se aprende exclusivamente o conhecimento intelectual, o corpo também é ensinado na escola. O modo de sentar, o modo de reprimir ou estimular algo, dependendo de quem o pratique, e se esta prática está de acordo com o que se espera de seu gênero descortinam muitas vezes relações de gêneros desiguais. Infelizmente o aparato escolar vem majoritariamente reforçando ideias que 
contribuem para a manutenção de diversas injustiças, reforçando estereótipos exercidos.

Por um aprendizado eficaz, continuado e sutil, um ritmo, uma cadência, uma disposição física, uma postura parecem penetrar nos sujeitos, ao mesmo tempo em que esses reagem e, envolvidos por tais dispositivos e práticas, constituem suas identidades 'escolarizadas'. Gestos, movimentos, sentidos são produzidos no espaço escolar e incorporados por meninos e meninas, tornando-se parte de seus corpos.” (Louro, 1997, p.61)

Não consideramos fácil refletir sobre as Relações de Gênero seja nos espaços escolares seja nos assentamentos rurais entre agricultores e agricultoras familiares, mesmo porque a repressão sobre o feminino não é nova, pelo contrário, remonta aos primórdios de nossa história.

“(...) durante um longo período (no passado de nossa sociedade), o termo sexo referia-se exclusivamente às mulheres - estas não tinham um sexo, eram o sexo (e, por isso mesmo, figuras por excelência do Mal e da busca desenfreada do prazer, amolecendo corpo e espírito dos homens guerreiros) precisando ser controladas, punidas, vigiadas de todas as maneiras possíveis.” (Chauí, 1991 p. 27)

A busca por Relações de Gênero mais equitativas não beneficia apenas as mulheres, toda a humanidade ganha com Relações de Gênero mais justa. Relações de Gênero são relações de poder e o lugar do homem como dominador absoluta destas Relações também faz deste “ (...) uma vítima potencial - constantemente aberto para o ataque simbólico, não apenas por outros homens, mas também por mulheres.” (Parker, 1991, p. 82).

Neste sentido, nossa pesquisa pretende estudar as Relações de Gênero nos processos educativos desenvolvidos no meio rural e nas ações educativas de nosso instituto federal tentando compreender os conceitos de gênero que se concretizam se espaços e como estes influenciam a Formação de Professores de Química. Compreendemos este tema deva ser articulado a formação de professores de nosso curso tendo em vista a força que a diversidade cultural vem ganhando na interpretação dos fenômenos educativos

As questões que envolvem a diversidade cultural brasileira tem sido alvo de inúmeros estudos na última década no cenário educacional. Cada vez mais conceitos como diversidade, diferença, igualdade e justiça social têm se configurado como uma preocupação por parte daqueles que lutam por uma educação verdadeiramente cidadã. Ao mesmo tempo, articular tais conceitos à formação de professores tem se tornado um desafio premente para a educação e para as instâncias envolvidas nesse processo. ( CANEN, XAVIER, 2011, p.641) 
Nosso estudos debruçam-se nas questões de Gênero porque considera esse tema essencial para a Educação e portanto necessário também a Formação de Professores de Química.

\begin{abstract}
Essa educação que buscamos pressupõe também questionar a ética que permeia o processo educativo. Como seres históricos e éticos, somos capazes de comparar, escolher, decidir e romper. Estas qualidades estão permeadas por relações de poder. É necessário, portanto, observar na prática pedagógica em que medida tais decisões influenciam ou são influenciadas pelas relações de poder racistas, sexistas e homofóbicas. Algumas questões permitem refletir sobre essa realidade na escola e reorientar o processo pedagógico na escola, por exemplo. (BEZERRA, DANTAS, 2007, p. 25)
\end{abstract}

\title{
Metodologia
}

Nosso estudo tem como referência metodológica a pesquisa qualitativa de cunho participante, ou seja, nossos passos metodológicos serão dados nas comunidades rurais onde o projeto será desenvolvido e nas ações educativas desenvolvidas no âmbito da própria Licenciatura em Química, de onde esperamos, dado a profundidade de nosso mergulho teórico/metodológico, elencar questões relevantes para o processo educativo de construção das relações de gênero no meio rural e na formação de professores.

A primeira fase de nosso estudo é realizar uma revisão da literatura científica focada nas Relações de Gênero no meio Rural; Relações de Gênero e Formação de Professores, buscando os espaços de intersecções, complementaridade e afastamento destes temas. Paralelamente iremos acompanhar a realização e sistematização de um diagnóstico rápido participativo no meio rural, buscando observar e identificar os fenômenos de Gênero neste espaço. Estaremos também estudando as ações educativas desenvolvidas no IFPE campus Barreiros buscando identificar como as Relações de Gênero são tratadas, como são apresentadas ou são invisibilizadas, fazendo deste espaço um laboratório teórico e metodológico de estudo das Relações de Gênero no meio rural das comunidades e no meio acadêmico de nosso instituto.

Os estudos teóricos ocorrerão de modo concomitante à imersão nas comunidades rurais, e nas ações educativas desenvolvidas em nosso instituto, de modo que a realidade concreta destas comunidades desafie e seja ao mesmo tempo esclarecida pelo aporte teórico estudado, podendo abrir caminho para novas formulações teórico-metodológicas.

Neste primeiro momento elencamos como ações educativas a serem estudadas o Festival de Literatura do IFPE campus Barreiros, evento levado a cabo pelos estudantes do Ensino Médio e orientado pelos professores de Língua Portuguesa. Nosso olhar buscará compreender como se concretiza o conceito de Relações de Gênero nesta ação educativa e qual sua influência na percepção das relações de gênero em nosso estudantes da Licenciatura de Química que participam deste evento.

\section{Resultados e Discussões}

Nossa pesquisa encontra-se na primeira fase. O mergulho teórico nos temas elencados 
em nosso estudo vem descortinando uma ampla gama de questões que contribuem para a melhoria da Formação de Professores e para a construção de Relações de Gênero mais justas em nossa sociedade. As mudanças culturais vem se processando de modo cada vez mais acelerado em nossa sociedade contemporânea. Tais mudanças, no entanto, nem sempre são avanços sociais, algumas são inclusive retrocessos lamentáveis de questões que pareciam vencidas no século passado e que retornam com mais força em pleno século XXI. Nossos estudos pretendem fortalecer as conquistas sociais que têm ajudado em nosso processo de civilidade, onde a Formação de Professores engajados com a construção de um mundo melhor tem papel central.

\section{Conclusão}

A zona da mata sul pernambucana é uma região que carrega traços culturais fortemente encharcados de machismo e sexismo ainda pouco identificados nos processos educativos que ocorrem no dia-a-dia destas comunidades rurais. Os aparatos oficiais de combate à violência contra a mulher são frágeis ou inexistente na região, o que estimula a violência por um lado e fortalece a sub-notificação das mesmas, por outro. Nosso estudo vem produzindo aportes teórico/metodológicos relevantes no campo das Relações de Gênero produzidas nos processos educativos, o que contribue de modo decisivo para a Formação de Professores de Química críticos e engajados na construção social e etica de um mundo mais justo.

\section{Bibliografia}

AZERÊDO, Sandra. Preconceito Contra a “Mulher”: diferença, poemas e corpos. São Paulo, Cortez, 2011.

BEZERRA, Nielson da Silva. DANTAS, Silvia Marques. Educação Inclusiva: não-sexista, antiracista e não-homofóbica. In BEZERRA, Nielson da Silva (org). Respeitando as Diferenças no Espaço Escolar. Recife: Gestos, 2007. p.21-40.

CANEN, Ana. XAVIER, Giseli Pereli de Moura. Formação Continuada de Professores para a Diversidade Cultural: ênfases, silêncios e perspectivas. In Revista Brasileira de Educação. V.16. $\mathrm{n}^{\circ}$ 48. set-dez. 2011

CHAUÍ, Marilena. Repressão sexual: essa nossa (des) conhecida. São Paulo, Brasiliense, 1991. 
LOURO, Guaciara Lopes. Gênero, sexualidade e educação: uma perspectiva pós-estruturalista. Petrópolis, Vozes, 1997.

PARKER, Richard G. Corpos, prazeres e paixões: a cultura sexual no Brasil contemporâneo. São Paulo, Editora Best Seller, 1991. 